\title{
RESEARCH
}

Open Access

\section{Low urinary iodine is a protective factor of central lymph node metastasis in papillary thyroid cancer: a cross-sectional study}

Ziyang Zeng ${ }^{1}$, Kang Li ${ }^{2}$, Xianze Wang ${ }^{1}$, Siwen Ouyang ${ }^{1}$, Zimu Zhang ${ }^{1}$, Zhen Liu', Juan Sun ${ }^{1}$, Xin Ye ${ }^{1}$, Weiming Kang ${ }^{1^{*}}$ and Jianchun $\mathrm{Yu}^{1^{*}}$

\begin{abstract}
Background: An abrupt increase of thyroid cancer has been witnessed paralleling the supplemented iodine intake in formerly iodine-deficient countries. And increased iodine intake has been linked to the rising incidence rate of papillary thyroid cancer (PTC). However, the correlation between iodine and clinicopathological features of PTC has not been well-characterized. This study aimed to investigate the associations between iodine intake and the clinicopathological features of PTC patients.

Methods: Three hundred and fifty-nine PTC patients who received surgical treatment in Peking Union Medical College Hospital from May 2015 to November 2020 were retrospectively reviewed. The associations between urinary iodine $(\mathrm{UI})$, urinary iodine/creatinine ratio $(\mathrm{UI} / \mathrm{U}-\mathrm{Cr})$, and the clinicopathological features of PTC were analyzed. Univariate and multivariate analysis were performed to investigate the relationship between UI level and central lymph node metastasis (CLNM).

Results: There were no significant differences in UI in different groups according to the variables studied, except that patients with CLNM had higher UI level than CLNM(-) patients. No associations were found between UI/U-Cr and clinicopathological features except variant subtypes (classic/follicular). After dividing patients into high-iodine group and low-iodine group, more patients were found to have CLNM in the high-iodine group $(p=0.02)$. In addition, younger age, larger tumor size, and classic variant were positively correlated with CLNM $(p<0.05)$. Univariate analysis showed that insufficient iodine intake $(\leq 99 \mu \mathrm{g} / \mathrm{L})$ was associated with decreased CLNM risk in PTC. And after defining insufficient iodine intake as $\leq 109 \mu \mathrm{g} / \mathrm{L}$ and above requirements as $\geq 190 \mu \mathrm{g} / \mathrm{L}$, multivariate analysis showed that lower iodine was associated with CLNM in total population of PTC (OR $0.53,95 \% \mathrm{Cl} 0.31-0.91$ ) and in PTC $<1 \mathrm{~cm}$ (papillary thyroid microcarcinoma, PTMC) (OR 0.43, 95\% Cl 0.21-0.87).
\end{abstract}

Conclusions: Low iodine was a protective factor for CLNM in papillary thyroid cancer, particularly in those $<1 \mathrm{~cm}$. These results indicated that iodine may not only be an initiator of tumorigenesis, but also a promoter of the development of PTC.

Keywords: lodine intake, Universal salt iodization, Papillary thyroid cancer, Papillary thyroid microcarcinoma, Central lymph node metastasis

\footnotetext{
*Correspondence: pumchkangweiming@126.com; yu-jch@163.com 'Department of General Surgery, Peking Union Medical College Hospital, Chinese Academy of Medical Sciences and Peking Union Medical College, No. 1 Shuaifuyuan Wangfujing Dongcheng District, Beijing 100730, China Full list of author information is available at the end of the article
} 


\section{Background}

Thyroid cancer is by far the most common endocrine cancer and ranked the ninth in new cancer cases globally [1]. During the past decades, thyroid cancer has been rapidly growing and is estimated to be the 4th most common cancer in 2030 globally [2]. The reason for the high increasing rate has been inconclusive over time. Risk factors have been revealed such as radiation exposure [3], industrialized lifestyle such as obesity [4], pollutants [5], and population aging as well as growing scrutiny of thyroid and improved diagnostics [6]. Apart from these known ones, iodine intake has been suggested as an important impact factor for the rise of thyroid cancer.

The thyroid plays an important role in human health, regulating metabolism, body temperature, growth, development, and organ functions. Meanwhile, iodine is the indispensable trace element for the synthesis of thyroid hormone, and deficiency of iodine can result in nodule goiter, cognitive impairments, and delayed physical development [7]. For the purpose of correcting iodinedeficient disorders, iodine prophylaxis was introduced in countries with deficient environmental iodine. However, paralleling the increase of population iodine intake, many countries reported the increase of thyroid cancer, particularly papillary thyroid cancer (PTC) [8-11]. The same trend of PTC also took place in China [12], after the universal salt iodization (USI) program was introduced in 1996. Although dietary iodine greatly improved endemic thyroid disorders, it has been debated whether over intake of iodine promoted thyroid cancer. However, because thyroid screening and imaging system were also advancing during the time, epidemiological studies were limited to reveal the true effects of increased iodine intake. As the excretion of urinary iodine accounted for $80-90 \%$ of daily iodine intake, urinary iodine is a convenient, economic and excellent biomarker to reflect the iodine intake of the population, and the World Health Organization (WHO) has recommended urinary iodine (UI), preferably median urinary iodine (MUI) to assess iodine intake [13]. Studies by Wang et al. [14] found higher UI in patients with PTC than benign nodules and found higher iodine level in $\operatorname{LNM}(+)$ PTC than in LNM(-) PTC. However, Zhao et al. [15] did not observe significant difference of UI between benign nodules and PTC nor did they find the difference of UI between $\operatorname{LNM}(+)$ and LNM(-) PTC [16]. The controversies between studies indicated that more variables should be considered in the analysis of iodine and thyroid cancer.

On the other hand, relating iodine to creatinine is yet another estimate of iodine intake, because the measurement of UI could be affected by urine output. As a result, urinary iodine/creatinine ratio (UI/U-Cr) has been established to correct the variations of urine output, because urinary creatinine excretion rate is very constant
[17]. However, the majority of the studies have focused on UI, and limited studies have investigated the clinical value of $\mathrm{UI} / \mathrm{U}-\mathrm{Cr}$ in PTC.

In summary, the relationship between iodine intake and the characteristics of PTC has not been studied in detail. Also, the associations between UI/U-Cr and PTC are not well-characterized. The preliminary aim of this study is to analyze the associations between UI, UI/U$\mathrm{Cr}$, and the clinicopathological features of PTC, in order to explore the underlying effects of iodine on this rapidly growing malignancy.

\section{Methods}

\section{Study population}

From May 2015 to November 2020, 359 consecutive patients in Peking Union Medical College Hospital were retrospectively reviewed. Inclusion criteria were patients who received total thyroidectomy or lobectomy with central lymph node dissection; postoperatively diagnosed as papillary thyroid cancer by pathological examinations. Exclusion criteria included a previous history of thyroid operation, combination of hyperthyroidism or hypothyroidism, recent use of iodinecontaining medication or reagents, administration of antithyroid drugs of thyroid hormones, abnormal kidney or liver function, and history of exposure to radiation at head and neck. Basic information of the patients was collected from the electronic medical record system, including age, sex, body mass index (BMI), and previous medical history. Postoperative pathology included pathological diagnosis, variant subtypes, foci number, tumor diameter, microscopical capsular invasion, combination of other thyroid disorders (e.g., nodular goiters), and detection of central lymph node metastasis (CLNM). This study was approved by the Ethics Committee of Peking Union Medical College Hospital (No. SK1336). The informed consent requirement was waived because individual information in this study was not accessible.

\section{Surgical treatments}

Thyroid surgery was performed in accordance with the management guidelines for thyroid cancer in China. Unilateral or bilateral thyroid resection was determined upon preoperative examination and intraoperative frozen sections as well as intraoperative surgical findings. Prophylactic central lymph node dissection was carried out as recommended by the Chinese guidelines. After surgery, the size, the number, and the pathological types of the foci were detected by the department of pathology. Tumor size was determined by its largest diameter. Multifocality was defined as the presence of $\geq 2$ papillary thyroid cancer foci in the specimen, and in these cases, tumor size was represented by the largest one of the foci. 


\section{Measurement of urinary iodine and urinary creatinine} The World Health Organization has recommended using median urinary iodine concentration (MUI) as a measurement for the iodine nutritional status of the population, with urinary iodine $\leq 99 \mu \mathrm{g} / \mathrm{L}, 100-199 \mu \mathrm{g} /$ $\mathrm{L}, 200-299 \mu \mathrm{g} / \mathrm{L}$, and $\geq 300 \mu \mathrm{g} / \mathrm{L}$ corresponding to insufficient, adequate, above requirements, and excessive iodine intake, respectively. Given that there was an intra-individual variation of $32 \%$ for urinary iodine excretion in a previous study [18], we adopted a modest modulation of the cutoff-point of WHO criteria in our analysis, where indicated. Fasting urine samples were collected during a routine visit before surgery, and the patients were required to abstain from iodine-sufficient food for at least 3 days before sample collection. On the day of sample collection, urine was collected in a clean 5-mL white-capped VACUEET tubes with no additive. Urinary iodine concentration was measured with inductively coupled plasma mass spectrometry (ICP-MS) method. The ICP-MS analysis was performed with an iCAP-Q ICP-MS system (Thermo Scientific, Waltham, MA) coupled with an automated sampler (CETAC ASX520; Thermo Scientific, Waltham, MA) [19]. Urinary creatinine (Maccura, China, enzymatic method) was measured using an automated chemistry analyzer (Beckman Coulter AU2700, Beckman Coulter, Brea, USA). For urinary iodine, samples were measured in triplicate, and the mean value was calculated as the iodine concentration for each sample.

\section{Statistical analysis}

Urinary iodine (UI) and urinary iodine/creatinine (UI/U-Cr) was expressed as median (upper and lower quartile) and analyzed with Wilcoxon rank-sum test because of their skewed distribution. Categorical variables were analyzed with chisquare test or Fisher's exact test. Univariate and multivariate analyses were performed using logistic regression analysis. As $\mathrm{UI} / \mathrm{U}-\mathrm{Cr}$ was strongly associated with age and sex composition of the investigated population, propensity score matching (PSM) was applied in the analysis of UI/U-Cr to reduce the bias between groups. Age and sex were included in the algorithm using nearest-neighbor matching method with a caliper size of 0.05 . The survival curve was depicted using the Kaplan-Meier method and compared using the log-rank test. A P value $\leq 0.05$ was considered statistically significant. All statistical analyses were performed with SPSS software (version 26.0, IBM Corporation) and $\mathrm{R}$ software (version 3.6.2, R Foundation for Statistical Computing).

\section{Results}

$\mathrm{UI}$ and UI/U-Cr level in different clinicopathologic status among PTC patients

Among the 359 patients diagnosed with PTC, UI was not significantly different between different age, sex, or other clinicopathological features, except that UI was significantly higher in CLNM(+) patients than in N0 patients $(152 \mu \mathrm{g} / \mathrm{L}$ vs $126 \mu \mathrm{g} / \mathrm{L}, \mathrm{p}=0.028)$. After correction with creatinine, female and patients aged $\geq 45$ exhibited significantly higher UI/U-Cr. Except variant subtypes ( $p$ $=0.021$ ), no other pathological features were significantly different regarding UI/U-Cr level. Of note, capsular invasion tended to correlate with lower UI, but the difference was not statistically significant $(\mathrm{p}=0.066)$ (Table 1).

\section{Correlations of UI, UI/U-Cr, and clinicopathological features of PTC patients}

Using the median value as the cutoff, the patients were classified into an iodine-high and an iodine-low group to compare the difference between clinical and histopathological features. There was no significant difference in age, sex, BMI, smoking status, tumor size, multifocality, and capsular invasion as well as variant subtypes in the two groups. In addition, iodine was not associated with coexisted nodular goiter, chronic thyroiditis, or thyroid adenoma. However, patients in the UI-high group were more likely to be positive for CLNM compared with the UI-low group $(\mathrm{p}=0.017)$ (Table 2$)$.

As is shown in Table 3 , female and patients aged $\geq 45$ showed significantly higher UI/U-Cr $(\mathrm{p}<0.001$ and $\mathrm{p}<$ 0.01 ), which was due to the physiologically lower $\mathrm{U}-\mathrm{Cr}$ among women and elders (Table 1). To reduce the imbalance of baseline data between the two groups (Table 3), a 1:1 PSM was performed to adjust for age and sex. After PSM, 118 age- and sex-adjusted patients in each of the two groups were identified, with no statistically differences in baseline characteristics. However, no significant differences were found in histopathological features and the distribution of CLNM ( $\mathrm{p}=0.295)$ (Table 3).

\section{Risk factors of central lymph node metastasis in PTC patients}

According to the results above, CLNM was closely related to a higher level of UI. However, CLNM is a pathological process affected by multiple risk factors, which could be potential confounders in the relationship of urinary iodine level and lymph node metastasis. To better understand the relationship between UI and CLNM, we further explored the risk factors that may contribute to the presence of CLNM. As Table 4 shows, age was significantly lower in patients with CLNM ( $<<0.001$ ). Tumor size was significantly larger in patients with CLNM ( $<$ 0.001). The classic variant of PTC was more likely to present with CLNM than the follicular variant $(\mathrm{p}<0.001)$. Furthermore, CLNM was marginally correlated with multiple foci $(\mathrm{p}=0.064)$ (Table 4). 
Table 1 Comparisons of UI and UI/U-Cr between different clinicopathological status of PTC patients

\begin{tabular}{|c|c|c|c|c|c|}
\hline Variables & $\mathrm{n}$ & $\mathrm{UI}, \mu \mathrm{g} / \mathrm{L}$ & $P$ value & $\mathrm{UI} / \mathrm{Cr}, \mu \mathrm{g} / \mathrm{g}$ & $P$ value \\
\hline \multicolumn{6}{|l|}{ Age } \\
\hline$\geq 45$ & 155 & 131 (87-198) & 0.266 & $97(75-138)$ & $<0.001$ \\
\hline$<45$ & 204 & 147 (97-210) & & $80(56-124)$ & \\
\hline \multicolumn{6}{|l|}{ Sex } \\
\hline Male & 104 & $146(103-201)$ & 0.353 & $76(51-111)$ & $<0.001$ \\
\hline Female & 255 & 140 (86-208) & & $95(70-142)$ & \\
\hline \multicolumn{6}{|l|}{ BMI, $\mathrm{kg} / \mathrm{m}^{2}$} \\
\hline$\geq 24$ & 205 & $132(90-197)$ & 0.261 & $86(62-124)$ & 0.202 \\
\hline$<24$ & 154 & $152(96-218)$ & & $93(67-137)$ & \\
\hline \multicolumn{6}{|l|}{ Tobacco use } \\
\hline Yes & 38 & $136(94-218)$ & 0.782 & $86(54-123)$ & 0.15 \\
\hline No & 321 & 140 (87-196) & & $91(64-132)$ & \\
\hline \multicolumn{6}{|l|}{ Tumor size } \\
\hline$\geq 1 \mathrm{~cm}$ & 125 & 139 (86-197) & 0.711 & $95(61-132)$ & 0.602 \\
\hline$<1 \mathrm{~cm}$ & 234 & 142 (94-209) & & $87(63-127)$ & \\
\hline \multicolumn{6}{|l|}{ Multifocality } \\
\hline Yes & 131 & 148 (96-208) & 0.53 & $95(68-136)$ & 0.137 \\
\hline No & 228 & 136 (90-205) & & $86(61-124)$ & \\
\hline \multicolumn{6}{|l|}{ Capsular invasion } \\
\hline Yes & 253 & 139 (84-195) & 0.066 & $90(61-131)$ & 0.65 \\
\hline No & 106 & $148(104-219)$ & & $90(64-127)$ & \\
\hline \multicolumn{6}{|l|}{ Pathological subtype } \\
\hline Classic variant & 261 & 142 (94-209) & 0.484 & $86(61-131)$ & 0.021 \\
\hline Follicular variant & 65 & $126(77-197)$ & & $90(62-124)$ & \\
\hline Classic and follicular variant & 33 & $166(87-215)$ & & $102(85-143)$ & \\
\hline \multicolumn{6}{|l|}{ CLNM } \\
\hline Yes & 166 & $152(105-215)$ & 0.028 & $94(61-141)$ & 0.523 \\
\hline No & 193 & $126(84-197)$ & & $90(64-123)$ & \\
\hline
\end{tabular}

Univariate and multivariate logistic regression analyses on the urinary iodine level for the presence of CLMN in PTC patients

First, we investigated the association of age, tumor size, multifocality, variant subtype, and the presence of CLNM by univariate logistic regression analysis. In total PTC patients, age, tumor size, and classic variant were significantly associated with CLNM with an OR of 0.96 (95\% CI 0.94-0.98), 2.01 (95\% CI 1.31-3.14), and 3.57 (95\% CI 1.95-6.88). Meanwhile, multifocality was marginally related to positive CLNM (OR 1.50, 95\% CI 0.98-2.32).

The optimal cutoff value of UI for the diagnosis of CLNM was determined as $130.5 \mu \mathrm{g} / \mathrm{L}$ (Supplementary figure 1). Then, based on the WHO criteria, we found that insufficient iodine $(\leq 99 \mu \mathrm{g} / \mathrm{L})$ tended to be inversely associated with CLNM by univariate regression analysis (Table 5). However, no significant associations were found after adjusted for age, sex, multifocality, tumor size, and variant subtype. After we defined insufficient iodine as $\leq 109 \mu \mathrm{g} / \mathrm{L}$ and above requirements as $\geq$ $190 \mu \mathrm{g} / \mathrm{L}$, we found that low UI was a protective factor for CLNM by univariate analysis (OR 0.44, 95\% CI $0.26-$ 0.72 ) and remained an independent protective factor in multivariate analysis (OR 0.53 , 95\% CI 0.31-0.91). In subgroup analysis, lower iodine was also correlated with No both in PTC $\geq 1 \mathrm{~cm}$ and PTC $<1 \mathrm{~cm}$ by univariate analysis. And multivariate analysis revealed that low UI remained an independent protective factor for CLNM in PTC $<1 \mathrm{~cm}$ (OR 0.43, 95\% CI 0.21-0.87) (Table 5). As Fig. 1 shows, PTC with $\leq 109 \mu \mathrm{g} / \mathrm{L}$ had the smallest proportion of CLNM, while the group with $\geq 190 \mu \mathrm{g} / \mathrm{L}$ and 110-189 $\mu \mathrm{g} / \mathrm{L}$ showed medium and higher proportion of CLNM. However, the recurrence-free survival was not significantly different between the three groups ( $\mathrm{p}=$ 0.49) (Supplementary figure 2). 
Table 2 Association of UI and clinicopathological features of PTC

\begin{tabular}{|c|c|c|c|c|}
\hline \multirow[t]{3}{*}{ Variables } & \multicolumn{4}{|c|}{ Urinary iodine, $\mu \mathrm{g} / \mathrm{L}$} \\
\hline & \multirow[t]{2}{*}{$\mathrm{n}(\%)$} & \multirow{2}{*}{$\begin{array}{l}\text { Low (\%) } \\
n=181\end{array}$} & \multirow{2}{*}{$\begin{array}{l}\text { High (\%) } \\
n=178\end{array}$} & \multirow{2}{*}{$\begin{array}{l}P \\
\text { value }\end{array}$} \\
\hline & & & & \\
\hline \multicolumn{5}{|l|}{ Age } \\
\hline$\geq 45$ & $155(43.2)$ & $82(22.8)$ & $73(20.3)$ & 0.273 \\
\hline$<45$ & $204(56.8)$ & $96(26.7)$ & $108(30.1)$ & \\
\hline \multicolumn{5}{|l|}{ Sex } \\
\hline Male & $104(29)$ & $48(13.4)$ & $56(15.6)$ & 0.407 \\
\hline Female & $255(71)$ & $130(36.2)$ & $125(34.8)$ & \\
\hline \multicolumn{5}{|l|}{ BMl, $\mathrm{kg} / \mathrm{m}^{2}$} \\
\hline$\geq 24$ & $205(57.1)$ & 109 (30.4) & $96(26.7)$ & 0.117 \\
\hline$<24$ & $154(42.9)$ & $69(19.2)$ & $85(23.7)$ & \\
\hline \multicolumn{5}{|l|}{ Diabetes } \\
\hline Yes & $16(4.5)$ & $9(2.5)$ & $7(1.9)$ & 0.585 \\
\hline No & $343(95.5)$ & $169(47.1)$ & $174(48.5)$ & \\
\hline \multicolumn{5}{|l|}{ Hypertension } \\
\hline Yes & $63(17.5)$ & $37(10.3)$ & $26(7.2)$ & 0.11 \\
\hline No & $296(82.5)$ & $141(39.3)$ & $155(43.2)$ & \\
\hline \multicolumn{5}{|l|}{ Tobacco use } \\
\hline Yes & $38(10.6)$ & $19(5.3)$ & $19(5.3)$ & 0.957 \\
\hline No & $321(89.4)$ & $159(44.3)$ & $162(45.1)$ & \\
\hline \multicolumn{5}{|l|}{ Tumor size } \\
\hline$\geq 1 \mathrm{~cm}$ & $125(34.8)$ & $64(17.8)$ & $61(17)$ & 0.654 \\
\hline$<1 \mathrm{~cm}$ & $234(65.2)$ & $114(31.8)$ & $120(33.4)$ & \\
\hline \multicolumn{5}{|l|}{ Multifocality } \\
\hline Yes & $131(36.5)$ & $60(16.7)$ & $71(19.8)$ & 0.277 \\
\hline No & $228(63.5)$ & $118(32.9)$ & $110(30.6)$ & \\
\hline \multicolumn{5}{|l|}{ Capsular invasion } \\
\hline Yes & $253(70.5)$ & $129(35.9)$ & $124(34.5)$ & 0.41 \\
\hline No & $106(29.5)$ & $49(13.6)$ & $57(15.9)$ & \\
\hline \multicolumn{5}{|l|}{ Nodular goiter } \\
\hline Yes & $99(27.6)$ & $52(14.5)$ & $47(13.1)$ & 0.491 \\
\hline No & $260(72.4)$ & $126(35.1)$ & $134(37.3)$ & \\
\hline \multicolumn{5}{|l|}{ Chronic thyroiditis } \\
\hline Yes & $94(26.2)$ & $50(13.9)$ & $44(12.3)$ & 0.415 \\
\hline No & $265(73.8)$ & $128(35.7)$ & $137(38.2)$ & \\
\hline \multicolumn{5}{|l|}{ Thyroid adenoma } \\
\hline Yes & $5(1.4)$ & $3(0.8)$ & $2(0.6)$ & 0.683 \\
\hline No & 354 (98.6) & $175(48.7)$ & 179 (49.9) & \\
\hline \multicolumn{5}{|l|}{ Variant subtype } \\
\hline Classic & $261(72.7)$ & $127(35.4)$ & $134(37.3)$ & 0.173 \\
\hline Follicular & $65(18.1)$ & $38(10.6)$ & $27(7.5)$ & \\
\hline Classic and follicular (multiple foci) & $33(9.2)$ & $13(3.6)$ & $20(5.6)$ & \\
\hline \multicolumn{5}{|l|}{ CLNM } \\
\hline Yes & $166(46.2)$ & $71(19.8)$ & $95(26.5)$ & 0.017 \\
\hline No & $193(53.8)$ & $107(29.8)$ & $86(24)$ & \\
\hline
\end{tabular}


Table 3 Correlation of UI/U-Cr and clinicopathological features of PTC

\begin{tabular}{|c|c|c|c|c|c|c|c|c|}
\hline \multirow[t]{4}{*}{ Variables } & \multicolumn{4}{|c|}{ Before PSM } & \multicolumn{4}{|l|}{ After PSM } \\
\hline & \multirow[t]{3}{*}{$\mathrm{n}$} & \multicolumn{2}{|c|}{$\mathrm{UI} / \mathrm{U}-\mathrm{Cr}, \mu \mathrm{g} / \mathrm{g}$} & \multirow{3}{*}{$\begin{array}{l}P \\
\text { value }\end{array}$} & \multirow[t]{3}{*}{$\mathrm{n}$} & \multicolumn{2}{|c|}{$\mathrm{UI} / \mathrm{U}-\mathrm{Cr}, \mu \mathrm{g} / \mathrm{g}$} & \multirow{3}{*}{$\begin{array}{l}P \\
\text { value }\end{array}$} \\
\hline & & Low & High & & & Low & High & \\
\hline & & $n=176$ & $n=183$ & & & $n=118$ & $n=118$ & \\
\hline \multicolumn{9}{|l|}{ Age } \\
\hline$\geq 45$ & $155(43.2)$ & $60(16.7)$ & $95(26.5)$ & 0.001 & $105(44.5)$ & 49 (20.8) & $56(23.7)$ & 0.359 \\
\hline$<45$ & $204(56.8)$ & $116(32.3)$ & $88(24.5)$ & & $131(55.5)$ & $69(29.2)$ & $62(26.3)$ & \\
\hline \multicolumn{9}{|l|}{ Sex } \\
\hline Male & $104(29)$ & $63(17.5)$ & $41(11.4)$ & 0.005 & $59(25)$ & $27(11.4)$ & $32(13.6)$ & 0.452 \\
\hline Female & $255(71)$ & $113(31.5)$ & $142(39.6)$ & & $177(75)$ & 91 (38.6) & $86(36.4)$ & \\
\hline \multicolumn{9}{|l|}{$\mathrm{BMI}, \mathrm{kg} / \mathrm{m}^{2}$} \\
\hline$\geq 24$ & $205(57.1)$ & $105(29.2)$ & $100(27.9)$ & 0.337 & $130(55.1)$ & $67(28.4)$ & $63(26.7)$ & 0.601 \\
\hline$<24$ & $154(42.9)$ & $71(19.8)$ & $83(23.1)$ & & $106(44.9)$ & $51(21.6)$ & $55(23.3)$ & \\
\hline \multicolumn{9}{|l|}{ Diabetes } \\
\hline Yes & $16(4.5)$ & $3(0.8)$ & $13(3.6)$ & 0.013 & $10(4.2)$ & $2(0.8)$ & $8(3.4)$ & 0.102 \\
\hline No & $343(95.5)$ & $173(48.2)$ & $170(47.4)$ & & $226(95.8)$ & $116(49.2)$ & $110(46.6)$ & \\
\hline \multicolumn{9}{|l|}{ Hypertension } \\
\hline Yes & $63(17.5)$ & $29(8.1)$ & $34(9.5)$ & 0.601 & $41(17.4)$ & $19(8.1)$ & $22(9.3)$ & 0.606 \\
\hline No & $296(82.5)$ & $147(40.9)$ & $149(41.5)$ & & $195(82.6)$ & $99(41.9)$ & $96(40.7)$ & \\
\hline \multicolumn{9}{|l|}{ Tobacco use } \\
\hline Yes & $38(10.6)$ & $21(5.8)$ & $17(4.7)$ & 0.416 & $25(10.6)$ & $12(5.1)$ & $13(5.5)$ & 0.832 \\
\hline No & $321(89.4)$ & $155(43.2)$ & $166(46.2)$ & & $211(89.4)$ & $106(44.9)$ & $105(44.5)$ & \\
\hline \multicolumn{9}{|l|}{ Tumor size } \\
\hline$\geq 1 \mathrm{~cm}$ & $125(34.8)$ & $55(15.3)$ & $70(19.5)$ & 0.164 & $88(37.3)$ & $40(16.9)$ & $48(20.3)$ & 0.282 \\
\hline$<1 \mathrm{~cm}$ & $234(65.2)$ & $121(33.7)$ & $113(31.5)$ & & $148(62.7)$ & $78(33.1)$ & $70(29.7)$ & \\
\hline \multicolumn{9}{|l|}{ Multifocality } \\
\hline Yes & $131(36.5)$ & $57(15.9)$ & $74(20.6)$ & 0.113 & $93(39.4)$ & $43(18.2)$ & $50(21.2)$ & 0.351 \\
\hline No & $228(63.5)$ & $119(33.1)$ & $109(30.4)$ & & $143(60.6)$ & $75(31.8)$ & $68(28.8)$ & \\
\hline \multicolumn{9}{|l|}{ Capsular invasion } \\
\hline Yes & $253(70.5)$ & $123(34.3)$ & $130(36.2)$ & 0.811 & $162(68.6)$ & 83 (35.2) & $79(33.5)$ & 0.575 \\
\hline No & $106(29.5)$ & $53(14.8)$ & $53(14.8)$ & & $74(31.4)$ & 35 (14.8) & $39(16.5)$ & \\
\hline \multicolumn{9}{|l|}{ Nodular goiter } \\
\hline Yes & $99(27.6)$ & $50(13.9)$ & $49(13.6)$ & 0.729 & $66(28)$ & $34(14.4)$ & $32(13.6)$ & 0.772 \\
\hline No & $260(72.4)$ & $126(35.1)$ & $134(37.3)$ & & $170(72)$ & $84(35.6)$ & $86(36.4)$ & \\
\hline \multicolumn{9}{|l|}{ Chronic thyroiditis } \\
\hline Yes & $94(26.2)$ & $40(11.1)$ & $54(15)$ & 0.144 & $63(26.7)$ & $28(11.9)$ & $35(14.8)$ & 0.303 \\
\hline No & $265(73.8)$ & $136(37.9)$ & $129(35.9)$ & & $173(73.3)$ & $90(38.1)$ & $83(35.2)$ & \\
\hline \multicolumn{9}{|l|}{ Thyroid adenoma } \\
\hline Yes & $5(1.4)$ & $4(1.1)$ & $1(0.3)$ & 0.207 & $3(1.3)$ & $2(0.8)$ & $1(0.4)$ & 1 \\
\hline No & 354 (98.6) & $172(47.9)$ & $182(50.7)$ & & $233(98.7)$ & $116(49.2)$ & $117(49.6)$ & \\
\hline Variant subtype & & & & & & & & \\
\hline Classic & $261(72.7)$ & $136(37.9)$ & $125(34.8)$ & 0.054 & $164(69.5)$ & $84(35.6)$ & $80(33.9)$ & 0.432 \\
\hline Follicular & $65(18.1)$ & $30(8.4)$ & $35(9.7)$ & & $48(20.3)$ & $25(10.6)$ & $23(9.7)$ & \\
\hline Classic and follicular (multiple foci) & $33(9.2)$ & $10(2.8)$ & $23(6.4)$ & & $24(10.2)$ & $9(3.8)$ & $15(6.4)$ & \\
\hline CLNM & & & & & & & & \\
\hline Yes & $166(46.2)$ & $80(22.3)$ & $86(24)$ & 0.77 & $106(44.9)$ & 49 (20.8) & $57(24.2)$ & 0.295 \\
\hline No & $193(53.8)$ & $96(26.7)$ & $97(27)$ & & $130(55.1)$ & $69(29.2)$ & $61(25.8)$ & \\
\hline
\end{tabular}


Table 4 Risk factors of central lymph node metastasis for PTC patients

\begin{tabular}{|c|c|c|c|}
\hline \multirow[t]{2}{*}{ Variables } & \multicolumn{2}{|c|}{ CLNM } & \multirow{2}{*}{$\begin{array}{l}P \\
\text { value }\end{array}$} \\
\hline & Yes & No & \\
\hline \multicolumn{4}{|l|}{ Age } \\
\hline$\geq 45$ & 53 & 102 & \multirow[t]{2}{*}{$<0.001$} \\
\hline$<45$ & 113 & 91 & \\
\hline \multicolumn{4}{|l|}{ Sex } \\
\hline Male & 53 & 51 & \multirow[t]{2}{*}{0.252} \\
\hline Female & 113 & 142 & \\
\hline \multicolumn{4}{|l|}{ BMI, $\mathrm{kg} / \mathrm{m}^{2}$} \\
\hline$\geq 24$ & 92 & 113 & \multirow[t]{2}{*}{0.551} \\
\hline$<24$ & 74 & 80 & \\
\hline \multicolumn{4}{|l|}{ Tumor size } \\
\hline$\geq 1 \mathrm{~cm}$ & 74 & 51 & \multirow[t]{2}{*}{$<0.001$} \\
\hline$<1 \mathrm{~cm}$ & 92 & 142 & \\
\hline \multicolumn{4}{|l|}{ Multifocality } \\
\hline Yes & 69 & 62 & \multirow[t]{2}{*}{0.064} \\
\hline No & 97 & 131 & \\
\hline \multicolumn{4}{|l|}{ Capsular invasion } \\
\hline Yes & 120 & 133 & \multirow[t]{2}{*}{0.484} \\
\hline No & 46 & 60 & \\
\hline \multicolumn{4}{|l|}{ Nodular goiter } \\
\hline Yes & 41 & 58 & \multirow[t]{2}{*}{0.258} \\
\hline No & 125 & 135 & \\
\hline \multicolumn{4}{|l|}{ Chronic thyroiditis } \\
\hline Yes & 46 & 48 & \multirow[t]{2}{*}{0.542} \\
\hline No & 120 & 145 & \\
\hline \multicolumn{4}{|l|}{ Thyroid adenoma } \\
\hline Yes & 3 & 2 & \multirow[t]{2}{*}{0.666} \\
\hline No & 163 & 191 & \\
\hline \multicolumn{4}{|l|}{ Variant subtype } \\
\hline Classic & 135 & 126 & \multirow[t]{3}{*}{$<0.001$} \\
\hline Follicular & 15 & 50 & \\
\hline Classic and follicular (multiple foci) & 16 & 17 & \\
\hline
\end{tabular}

\section{Discussion}

It is well established that the association between iodine intake and the incidence rate of thyroid disorders follows a U-shaped pattern [20], which demonstrates that either higher or lower iodine is likely to cause thyroid pathogenesis. The major finding of this study is that low iodine was associated with less LNM in the clinical practice. Although some studies suggested high iodine promoted PTC development, whereas this only indicated the correlation of iodine overdose and cancer development. Few studies have investigated how iodine affects PTC in a normal range or below (UI $<200 \mu \mathrm{g} / \mathrm{L}$ ). With the most control to biases, the current study found that iodine range below sufficient could be protective for CLNM. This finding added yet another layer of regulatory relation between iodine intake and thyroid. On the other hand, UI/ $\mathrm{U}-\mathrm{Cr}$ did not exhibit a strong correlation with characteristics of PTC like urinary iodine did. As an improved formula, UI/U-Cr was first introduced to normalize the differences of urine output when measuring UI. However, age, sex, and even protein intakes have strong influences on creatinine production $[17,21]$. By adjusting for age and sex, we did not observe significant relevance of UI/U-Cr to the histopathology of PTC. Thus, this study indicated that there may be no apparent associations between UI/U$\mathrm{Cr}$ and PTC, which is in agreement with the notion that variations of UI could be evened out among population and that relating UI to creatinine is to some extent an unnecessary procedure [13].

Wang et al. [14] found significantly higher MUI in positive vs negative lymph node metastasis $(1584.62 \mu \mathrm{g} / \mathrm{L}$ vs $315.61 \mu \mathrm{g} / \mathrm{L})$ (2010-2011). Zhao et al. [16] conducted a similar investigation and did not find difference of MUI between positive and negative CLNM. However, after defining CLNM as metastatic $L N \geq 2$, they found those with CLNM(+) had a higher MUI $(191.7 \mu \mathrm{g} / \mathrm{L}$ vs $176.2 \mu \mathrm{g} / \mathrm{L})$ (2013-2018). It is possible that at different baseline levels, iodine could have different impacts on the tumor behavior. The different results of the studies could be attributed to different geographical environment, as the former was conducted in an iodine-sufficient coastal area and the latter conducted in an inland region. The present study, conducted inland, showed that the MUI of population was at a relatively low level. This may have caused the milder differences between groups in our analysis. Moreover, it should be noted that since 2012, the standard iodine concentration in iodized salt was reduced from $35 \mathrm{mg} / \mathrm{kg}$ to a range of 20 to $30 \mathrm{mg} / \mathrm{kg}$ in China. This further resulted in a decrease of MUI in the population. Nevertheless, by classifying iodine status into a higher and lower group, this study found more CLNM cases in the high-iodine group, suggesting that even within a lower range of iodine level, iodine may still have an impact on the pathological features of PTC.

As the risk of lymph node metastasis is multifactorial, distinguishing the risk factors for CLNM was necessary before we investigated the correlation of iodine and lymph node metastasis. Our study found CLNM was mostly correlated with age and tumor size, which was evidenced by previous meta-analyses [22-24]. Moreover, studies have indicated higher risk of LNM in classic PTC compared to follicular variant PTC, which resulted in poorer long term outcomes for classic PTC [25]. Thus, we have considered these important factors in the assessment of CLNM risk. Referring to the WHO 
Table 5 Univariate and multivariate logistic regression analysis on UI level for the presence of CLNM in PTC patients

\begin{tabular}{|c|c|c|c|c|c|c|}
\hline \multirow{2}{*}{$\begin{array}{l}\text { Urinary iodine } \\
\text { status }(\mu \mathrm{g} / \mathrm{L})\end{array}$} & \multicolumn{3}{|l|}{ Univariate } & \multicolumn{3}{|c|}{ Multivariate $^{c}$} \\
\hline & OR & $95 \% \mathrm{Cl}$ & $P$ value & OR & $95 \% \mathrm{Cl}$ & $P$ value \\
\hline \multicolumn{7}{|l|}{ Total patients $^{\mathrm{a}}$} \\
\hline$\leq 99(n=102)$ & 0.59 & $0.36-0.98$ & 0.043 & 0.71 & $0.41-1.23$ & 0.221 \\
\hline $100-199(n=164)$ & Reference & & & Reference & & \\
\hline$\geq 200(n=93)$ & 0.98 & $0.59-1.63$ & 0.934 & 0.99 & $0.59-1.83$ & 0.98 \\
\hline \multicolumn{7}{|l|}{$\mathrm{PTC} \geq 1 \mathrm{~cm}^{\mathrm{a}}$} \\
\hline$\leq 99(n=39)$ & 0.4 & $0.17-0.91$ & 0.031 & 0.51 & $0.20-1.30$ & 0.161 \\
\hline $100-199(n=56)$ & Reference & & & Reference & & \\
\hline$\geq 200(n=30)$ & 1.03 & $0.41-2.69$ & 0.956 & 1.26 & $0.44-3.73$ & 0.674 \\
\hline \multicolumn{7}{|l|}{ PTC $<1 \mathrm{~cm}^{\mathrm{a}}$} \\
\hline$\leq 99(n=63)$ & 0.7 & $0.36-1.33$ & 0.281 & 0.73 & $0.35-1.48$ & 0.381 \\
\hline $100-199(n=108)$ & Reference & & & Reference & & \\
\hline$\geq 200(n=63)$ & 0.98 & $0.52-1.85$ & 0.96 & 1.09 & $0.55-2.15$ & 0.815 \\
\hline \multicolumn{7}{|l|}{ Total patients ${ }^{b}$} \\
\hline$\leq 109(n=135)$ & 0.44 & $0.26-0.72$ & 0.001 & 0.53 & $0.31-0.91$ & 0.021 \\
\hline $110-189(n=120)$ & Reference & & & Reference & & \\
\hline$\geq 190(n=104)$ & 0.68 & $0.40-1.15$ & 0.154 & 0.71 & $0.41-1.29$ & 0.281 \\
\hline \multicolumn{7}{|l|}{ PTC $\geq 1 \mathrm{~cm}^{\mathrm{b}}$} \\
\hline$\leq 109(n=50)$ & 0.38 & $0.16-0.89$ & 0.028 & 0.59 & $0.22-1.58$ & 0.294 \\
\hline $110-189(n=42)$ & Reference & & & Reference & & \\
\hline$\geq 190(n=33)$ & 0.9 & $0.34-2.40$ & 0.826 & 1.33 & $0.45-4.06$ & 0.608 \\
\hline \multicolumn{7}{|l|}{ PTC $<1 \mathrm{~cm}^{\mathrm{b}}$} \\
\hline$\leq 109(n=85)$ & 0.44 & $0.23-0.83$ & 0.012 & 0.43 & $0.21-0.87$ & 0.019 \\
\hline $110-189(n=78)$ & Reference & & & Reference & & \\
\hline$\geq 190(n=71)$ & 0.61 & $0.32-1.18$ & 0.143 & 0.65 & $0.32-1.33$ & 0.242 \\
\hline
\end{tabular}

criteria $(\leq 99 \mu \mathrm{g} / \mathrm{L}$ for insufficient iodine intake, 100$199 \mu \mathrm{g} / \mathrm{L}$ for adequate iodine intake, and $\geq 200 \mu \mathrm{g} / \mathrm{L}$ for above requirements), there was a tendency that CLNM decreased with lower urinary iodine. Allowing for the natural variation of spot urinary iodine, we redefined insufficient iodine as $\leq 109 \mu \mathrm{g} / \mathrm{L}$ and above requirements as $\geq 190 \mu \mathrm{g} / \mathrm{L}$. And we found insufficient iodine to be significantly associated with CLNM(-) for PTC $<1 \mathrm{~cm}$ in subgroup analysis. We thus supposed that urinary iodine may be more closely related to CLNM in PTC < $1 \mathrm{~cm}$ instead of PTC $\geq 1 \mathrm{~cm}$. In the similar pattern, Zhao et al. [16] only observed high UI to be marginally associated with CLNM. The different observations could be explained from several aspects. First is the absence of stratification for PTC sized $\geq 1 \mathrm{~cm}$ and $<1 \mathrm{~cm}$. As is shown in our study, iodine status may be associated with CLNM more in PTC $<1 \mathrm{~cm}$ than in PTC $\geq 1 \mathrm{~cm}$, indicating that there are more influencing factors in PTC $\geq$ $1 \mathrm{~cm}$. Second, we included classic and follicular variant as covariate in our model, as the classic/follicular ratio could largely affect the prevalence of CLNM. However, the classification of classic and follicular variant was often absent in previous studies. Third, we redefined and widened the range for insufficient iodine intake and above requirements, in consideration of the natural variation of urinary iodine. In clinical practice, PTC $<1 \mathrm{~cm}$, or papillary thyroid microcarcinoma (PTMC) [26] are usually of good prognosis; however, $1 / 3$ to $2 / 3$ of PTMC could have lymph node metastasis on pathological examination [27, 28]. Therefore, it has been controversial as to whether prophylactic LN dissection should be performed on PTMC. The present study suggested that iodine should be considered a risk factor of CLNM for PTMC, and more precise stratification for iodine nutrition are needed to identify the at-risk groups for PTC patients.

In experimental researches, it was found that iodine could promote thyroid cancer growth by suppressing 


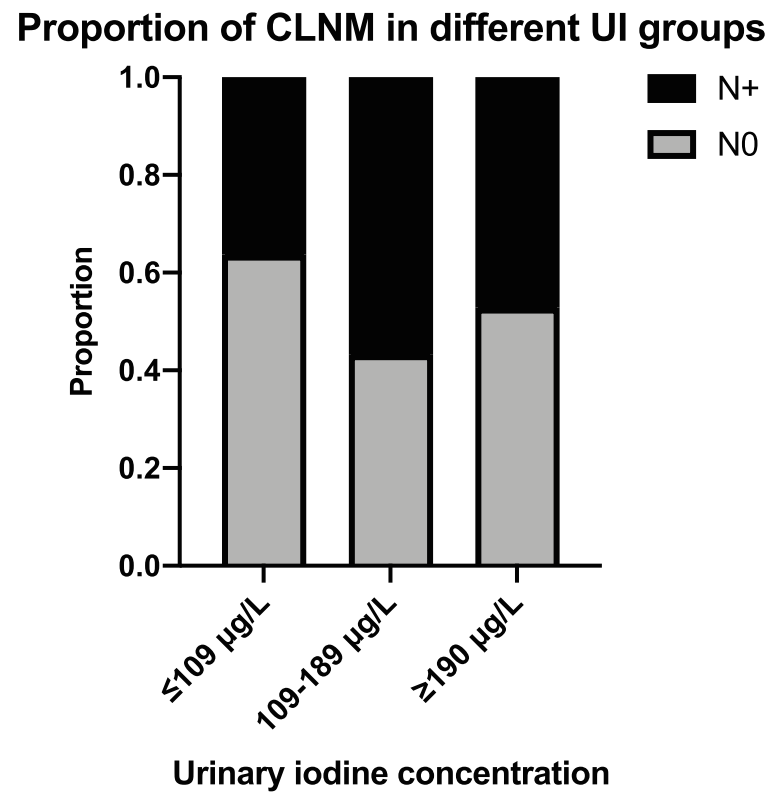

Fig. 1 Proportion of CLNM of PTC patients with different UI levels

miR-422a and up-regulating MAPK1 [29]. Moreover, iodine may have dual roles in mediating the proliferation of thyroid cancer in vitro. At concentration below $1.0 \times$ $10^{-3} \mathrm{mM}$ it could promote cell growth and migration, while at concentration above $1.0 \times 10^{-3} \mathrm{mM}$ iodine exhibited an inhibitory role [30]. And within a certain range of concentration, iodine could activate Akt and Erk signaling pathway [30], which are essential for tumorigenesis, invasion, metastasis, and epithelialmesenchymal transition [31, 32]. Furthermore, it was reported that BRAF mutation was more common in the high-water iodine region than in normal regions, while BRAF was closely related to lymph node metastases of PTC [33, 34]. These studies further confirmed iodine as a critical element during the development of thyroid cancer on the molecular basis; therefore, understanding the multi-layer mechanisms of iodine may facilitate better prevention and treatment of this malignancy.

In summary, our study showed that low UI level was a protective factor for CLNM of papillary thyroid cancer. The study also compared UI and UI/U-Cr simultaneously with the clinicopathological features of PTC and suggested that UI is a better parameter than UI/U-Cr to indicate lymph node metastasis of PTC. Our study was limited by the usual concerns related to cross-sectional studies: we cannot conclude a cause-and-effect relation between iodine and the pathological features of PTC, so further studies are still warranted to provide evidence of the regulatory mechanism between iodine and the aggressiveness of PTC. Furthermore, we did not observe significant difference of recurrence-free survival, so a longer follow up period will be required to investigate the prognosis of PTC patients with different UI levels. Although the effect of iodine on thyroid cancer is still controversial, our data further support the concept that iodine is related to lymph node metastasis of PTC, mainly through the protective effect of low iodine, which may provide novel insights into the management of iodine nutrition.

\section{Supplementary Information}

The online version contains supplementary material available at https://doi. org/10.1186/s12957-021-02302-6.

Additional file 1: Supplementary Figure 1. The receiver operating characteristic (ROC) curve for the diagnosis of CLNM. The ROC yielded an area under the curve (AUC) of 0.567. The sensitivity was 0.633 and the specificity was 0.523

Additional file 2: Supplementary Figure 2. Recurrence-free survival of the PTC patients with different UI levels.

\section{Acknowledgements}

Not applicable

Authors' contributions

$W K, X Y$, and $J Y$ conceived and designed the study. $Z Z$ and $K L$ analyzed the data and drafted the manuscript. XW and ZZ discussed and contributed to the data analysis. JS, SO, and ZL analyzed and interpreted the results. The authors read and approved the final manuscript.

Funding

Not applicable

\section{Availability of data and materials}

The datasets used and/or analyzed during the current study are available from the corresponding author on reasonable request.

\section{Declarations}

Ethics approval and consent to participate

The study was approved by the Ethics Committees of Peking Union Medical College Hospital (No. S-K1336). Because all the data were routinely obtained and no additional investigations or procedures were carried out, informed consent was not required.

Consent for publication

Not applicable

\section{Competing interests}

The authors declare that they have no competing interests.

\section{Author details}

${ }^{1}$ Department of General Surgery, Peking Union Medical College Hospital, Chinese Academy of Medical Sciences and Peking Union Medical College, No. 1 Shuaifuyuan Wangfujing Dongcheng District, Beijing 100730, China. ${ }^{2}$ Department of Vascular Surgery, Peking Union Medical College Hospital, Chinese Academy of Medical Sciences and Peking Union Medical College, Beijing, China.

Received: 7 April 2021 Accepted: 14 June 2021

Published online: 12 July 2021

\section{References}

1. Global Cancer Observatory. https://gco.iarc.fr/today/data/factsheets/ca ncers/32-Thyroid-fact-sheet.pdf.

2. Pearce A, Bradley C, Hanly P, O'Neill C, Thomas AA, Molcho M, et al. Projecting productivity losses for cancer-related mortality 2011 - 2030. BMC Cancer. 2016;16(1):804. https://doi.org/10.1186/s12885-016-2854-4. 
3. Sinnott B, Ron E, Schneider AB. Exposing the thyroid to radiation: a review of its current extent, risks, and implications. Endocr Rev. 2010;31(5):756-73. https://doi.org/10.1210/er.2010-0003.

4. Marcello MA, Cunha LL, Batista FA, Ward LS. Obesity and thyroid cancer. Endocr Relat Cancer. 2014;21(5):T255-71. https://doi.org/10.1530/ERC-140070 .

5. Zhu C, Zheng T, Kilfoy BA, Han X, Ma S, Ba Y, et al. A birth cohort analysis of the incidence of papillary thyroid cancer in the United States, 1973-2004. Thyroid. 2009;19(10):1061-6. https://doi.org/10.1089/thy.2008.0342.

6. Li M, Dal Maso L, Vaccarella S. Global trends in thyroid cancer incidence and the impact of overdiagnosis. Lancet Diabetes Endocrinol. 2020;8(6):468-70. https://doi.org/10.1016/S2213-8587(20)30115-7.

7. Zimmermann MB, Boelaert K. lodine deficiency and thyroid disorders. Lancet Diabetes Endocrinol. 2015;3(4):286-95. https://doi.org/10.1016/S22138587(14)70225-6.

8. Hofstadter F. Frequency and morphology of malignant tumours of the thyroid before and after the introduction of iodine-prophylaxis. Virchows Arch A Pathol Anat Histol. 1980;385(3):263-70. https://doi.org/10.1007/ BF00432536.

9. Radespiel-Troger M, Batzler WU, Holleczek B, Luttmann S, Pritzkuleit R, Stabenow $\mathrm{R}$, et al. Rising incidence of papillary thyroid carcinoma in Germany. Bundesgesundheitsbl Gesundheitsforsch Gesundheitsschutz. 2014; 57(1):84-92. https://doi.org/10.1007/s00103-013-1884-1.

10. Rego-Iraeta A, Perez-Mendez LF, Mantinan B, Garcia-Mayor RV. Time trends for thyroid cancer in northwestern Spain: true rise in the incidence of micro and larger forms of papillary thyroid carcinoma. Thyroid. 2009;19(4):333-40. https://doi.org/10.1089/thy.2008.0210.

11. Harach HR, Ceballos GA. Thyroid cancer, thyroiditis and dietary iodine: a review based on the Salta, Argentina model. Endocr Pathol. 2008;19(4):20920. https://doi.org/10.1007/s12022-008-9038-y.

12. Wang J, Yu F, Shang Y, Ping Z, Liu L. Thyroid cancer: incidence and mortality trends in China, 2005-2015. Endocrine. 2020;68(1):163-73.

13. WHO/UNICEF/ICCIDD: International Council for the Control of lodine Deficiency Disorders. Assessment of iodine deficiency disorders and monitoring their elimination. 3rd ed. Geneva: World Health Organization; 2007.

14. Wang F, Wang $Y$, Wang $L$, Wang $X$, Sun $C$, Xing $M$, et al. Strong association of high urinary iodine with thyroid nodule and papillary thyroid cancer. Tumour Biol. 2014;35(11):11375-9. https://doi.org/10.1007/s13277-014-23978.

15. Zhao H, Li H, Huang T. High urinary iodine, thyroid autoantibodies, and thyroid-stimulating hormone for papillary thyroid cancer risk. Biol Trace Elem Res. 2018;184(2):317-24. https://doi.org/10.1007/s12011-017-1209-6.

16. Zhao H, Li H, Huang T. High iodine intake and central lymph node metastasis risk of papillary thyroid cancer. J Trace Elem Med Biol. 2019;53: 16-21. https://doi.org/10.1016/j.jtemb.2019.01.015.

17. Knudsen N, Christiansen E, Brandt-Christensen M, Nygaard B, Perrild H. Ageand sex-adjusted iodine/creatinine ratio. A new standard in epidemiological surveys? Evaluation of three different estimates of iodine excretion based on casual urine samples and comparison to $24 \mathrm{~h}$ values. Eur J Clin Nutr. 2000;54(4):361-3. https://doi.org/10.1038/sj.ejcn.1600935.

18. Konig F, Andersson M, Hotz K, Aeberli I, Zimmermann MB. Ten repeat collections for urinary iodine from spot samples or 24-hour samples are needed to reliably estimate individual iodine status in women. J Nutr. 2011; 141(11):2049-54. https://doi.org/10.3945/jn.111.144071.

19. Yu S, Yin Y, Cheng Q, Han J, Cheng X, Guo Y, et al. Validation of a simple inductively coupled plasma mass spectrometry method for detecting urine and serum iodine and evaluation of iodine status of pregnant women in Beijing. Scand J Clin Lab Invest. 2018;78(6):501-7. https://doi.org/10.1080/ 00365513.2018 .1512150 .

20. He NL, Li H, An W, et al. [Study on constructing the U-shaped response relationship of urinary iodine level and thyroid nodule prevalence based on piecewise function quantile regression method]. Zhonghua Yu Fang Yi Xue Za Zhi. 2020;54(11):1268-74. https://doi.org/10.3760/cma.j.cn112150-202 00322-00403.

21. Konno N, Yuri K, Miura K, Kumagai M, Murakami S. Clinical evaluation of the iodide/creatinine ratio of casual urine samples as an index of daily iodide excretion in a population study. Endocr J. 1993;40(1):163-9. https://doi.org/1 0.1507/endocrj.40.163.
22. Mao J, Zhang Q, Zhang H, Zheng K, Wang R, Wang G. Risk factors for lymph node metastasis in papillary thyroid carcinoma: a systematic review and meta-analysis. Front Endocrinol. 2020;11:265.

23. Qu H, Sun GR, Liu Y, He QS. Clinical risk factors for central lymph node metastasis in papillary thyroid carcinoma: a systematic review and metaanalysis. Clin Endocrinol. 2015;83(1):124-32. https://doi.org/10.1111/cen.12 583.

24. Sun W, Lan X, Zhang H, Dong W, Wang Z, He L, et al. Risk factors for central lymph node metastasis in CNO papillary thyroid carcinoma: a systematic review and meta-analysis. PLoS One. 2015;10(10):e0139021. https://doi.org/1 0.1371/journal.pone.0139021.

25. Henke LE, Pfeifer JD, Baranski TJ, DeWees T, Grigsby PW. Long-term outcomes of follicular variant vs classic papillary thyroid carcinoma. Endocr Connect. 2018;7(12):1226-35. https://doi.org/10.1530/EC-18-0264.

26. Hedinger C, Williams ED, Sobin LH. The WHO histological classification of thyroid tumors: a commentary on the second edition. Cancer. 1989;63(5): 908-11. https://doi.org/10.1002/1097-0142(19890301)63:5<908::AID-CNCR282 0630520>3.0.CO;2-1.

27. Wada N, Duh QY, Sugino K, Iwasaki H, Kameyama K, Mimura T, et al. Lymph node metastasis from 259 papillary thyroid microcarcinomas: frequency, pattern of occurrence and recurrence, and optimal strategy for neck dissection. Ann Surg. 2003;237(3):399-407. https://doi.org/10.1097/01.SLA. 0000055273.58908.19.

28. Lim YC, Choi EC, Yoon YH, Kim EH, Koo BS. Central lymph node metastases in unilateral papillary thyroid microcarcinoma. Br J Surg. 2009;96(3):253-7. https://doi.org/10.1002/bjs.6484.

29. Wang J, Yang H, Si Y, Hu D, Yu Y, Zhang Y, et al. lodine promotes tumorigenesis of thyroid cancer by suppressing Mir-422a and up-regulating MAPK1. Cell Physiol Biochem. 2017;43(4):1325-36. https://doi.org/10.1159/ 000481844.

30. Xiang J, Wang X, Wang Z, Wu Y, Li D, Shen Q, et al. Effect of different iodine concentrations on well-differentiated thyroid cancer cell behavior and its inner mechanism. Cell Biochem Biophys. 2015;71(1):299-305. https://doi. org/10.1007/s12013-014-0198-8.

31. Jiang N, Dai Q, Su X, Fu J, Feng X, Peng J. Role of PI3KVAKT pathway in cancer: the framework of malignant behavior. Mol Biol Rep. 2020;47(6): 4587-629. https://doi.org/10.1007/s11033-020-05435-1.

32. Navandar M, Garding A, Sahu SK, Pataskar A, Schick S, Tiwari VK. ERK signalling modulates epigenome to drive epithelial to mesenchymal transition. Oncotarget. 2017;8(17):29269-81. https://doi.org/10.18632/oncota rget.16493.

33. Guan H, Ji M, Bao R, Yu H, Wang Y, Hou P, et al. Association of high iodine intake with the T1799A BRAF mutation in papillary thyroid cancer. J Clin Endocrinol Metab. 2009:94(5):1612-7. https://doi.org/10.1210/jc.2008-2390.

34. Frasca F, Nucera C, Pellegriti G, Gangemi P, Attard M, Stella M, et al. BRAF(V600E) mutation and the biology of papillary thyroid cancer. Endocr Relat Cancer. 2008;15(1):191-205. https://doi.org/10.1677/ERC-07-0212.

\section{Publisher's Note}

Springer Nature remains neutral with regard to jurisdictional claims in published maps and institutional affiliations.

Ready to submit your research? Choose BMC and benefit from:

- fast, convenient online submission

- thorough peer review by experienced researchers in your field

- rapid publication on acceptance

- support for research data, including large and complex data types

- gold Open Access which fosters wider collaboration and increased citations

- maximum visibility for your research: over $100 \mathrm{M}$ website views per year

At $\mathrm{BMC}$, research is always in progress.

Learn more biomedcentral.com/submissions 